\title{
AOR
}

Selected Papers of \#AolR2019:

The $20^{\text {th }}$ Annual Conference of the Association of Internet Researchers Brisbane, Australia / 2-5 October 2019

\section{BANKING ON CULTURAL INTERMEDIARIES ACROSS WEBTOON, WEBNOVEL AND VIDEO-SHARING PLATFORMS IN ASIA'S DIGITAL CREATIVE ECONOMY}

Associate Professor Brian Yecies

Communication and Media, University of Wollongong

Dr. Xiang (Tony) Ren

Australia-China Institute for Arts and Culture, Western Sydney University

Dr. Aegyung Shim

University of Wollongong

Dr. Dingkun Wang

Jiao Tong Baker Centre for Translation and Intercultural Studies, Shanghai Jiao Tong University

\section{Introduction}

The four papers in this interdisciplinary panel explore some of the dynamic reading, writing, sharing and transmedia adaptation trends emerging across popular digital webtoon (aka digital comics), webnovel (aka Internet novel) and video platforms in Asia and among Asian users. Specifically, the speakers investigate how complex layers of trust and (dis)trust are surrounding and impacting on the fans, also known as 'cultural intermediaries', involved in the production, circulation, translation and remake of Korean and Chinese webtoon and webnovel genres. Included in this discussion are fan-dubbed and video remixes of banned television shows that are inspiring local amateur content production. Together, the papers demonstrate how problematical layers of precarious labour are contributing to integral parts of Asia's expanding digital media cultures and industries - albeit in uneven and geographically dispersed ways. Ultimately, the panel will document how a range of outward-bound cultural and economic strategies driving some of Asia's largest digital platforms and new media formats are expanding the digital creative economy in the Asia-Pacific and beyond. 


\section{Associate Professor Brian Yecies: Asian Digital Transcreators on Korean Webtoon Platforms}

The first paper, "Asian Digital Transcreators on Korean Webtoon Platforms", sets the context for this panel by analysing some of the contributions that amateur usertranslators from Indonesia, Thailand and Vietnam are making to the thriving digital platform environment in the region. It explains how a coterie of trusted and respected Indonesian, Thai and Vietnamese "cultural intermediaries" are generating value for the Korean and global webtoon industry at large, while also inspiring a new generation of local writers and artists seeking to join this expanding arena. In turn, as this paper argues, such transcreators and transnational cultural practices are transforming new genres and aspects of digital media cultural practices in the Global South, symbiotically advancing the expansion of the Korean digital wave and its revitalised links with Southeast Asia.

\section{Dr. Xiang (Tony) Ren: Transmedia Online Literature in China and Global Platform Ecosystems}

The second paper, "Transmedia Online Literature in China and Global Platform Ecosystems", explores the defining features of digital Chinese online literature in the age of cross-platform distribution and fan-led transmedia adaptations. To shed light on this complex topic, and the new roles that Kuaikan and Bilibili are playing in this rapidly transforming arena, the talk first conceptualises the opportunities and challenges of this global phenomenon. Next, it maps the extended value chain of online transmedia literature that is accessible via connected distribution platforms and multiple media formats. The paper concludes by showing how the practices surrounding the promotion and reception of Chinese online literature on these two particular platforms represent a significant aspect of China's "going out" (aka global expansion) campaign. In so doing, the paper highlights the changing role that fan-translation platforms are playing in the global expansion of Chinese online literature and the interplay between international and domestic ecosystems of creative digital literature.

\section{Dr. Aegyung Shim: Webtoon Literary Adaptations and their East Asian Encounters}

The third paper, "Webtoon Literary Adaptations and their East Asian Encounters", builds upon the arguments about transcreation in the first paper. The presenter uses a case study of the popular webtoon series Cheese in the Trap as well as its television series and film remakes to illustrate how new transmedia flows are underpinning the expansion of literary adaptation in Asia, thus winning the hearts and minds of audiences in the region. Specifically, the speaker investigates some of the previously unrecognised contributions that fan-translators - or "transcreators" - are making to the inconspicuous spread of webtoon genres and narratives across the region, and how this form of precarious labour is being exploited by Naver. As such, the speaker analyses how a webtoon series is translated and then transformed across multiple formats and platforms, and how representative cultural intermediaries are magnifying the power and spread of webtoons throughout the Global South more broadly. 


\section{Dr. Dingkun Wang: The Complexity of Translation in the Fan-Made Video 'Meeting Sheldon' (2014)}

In the fourth and final paper, "The Complexity of Translation in the Fan-Made Video Meeting Sheldon (2014)", the speaker presents a case study of fan-driven metamorphosis of the popular sitcom The Big Bang Theory in the Chinese context. The fan-made video “寨见谢耳朵” (aka Meeting Sheldon, available at:

www.youtube.com/watch?v=tas7rCNYB0o) was produced by the fandubbing group Huai Xiu Bang (淮秀帮) as a response to the official ban of The Big Bang Theory from licensed online broadcast in China. Huai Xiu Bang remixed the disintegrated clips and audio assembled from the original series, while recreating a newly dubbed soundtrack in Chinese and English. As a result, as this paper argues, the group created a new story that deliberately ridiculed censorship in China, earning them a kind of respect and trust (or in some cases, distrust) among followers. The repurposed storyline represents a dynamic form of digital intermediation, through which fan translators breach the boundaries between their own cultural-political realities and the industrial context linked to the original storyworld - all while imposing upon the later their extradiegetic desire to transform the "target text". Today, thousands of YouTube audiences watching this fanmade video are treated to an unnatural narrative which places the original main characters at the intersections between the two worlds to convey anxious emotions towards the official ban through a series of jokes. 